\title{
INTERACTIVE EFFECTS OF SIZE, STORAGE METHOD AND DURATION ON QUALITY MND PHYSICAL CHARACTERISTICS OF TABLE EGCS
}

\author{
S.O. KEMEI and A.A. OSOKOMAIYA \\ Department of Animal Production, Ot. State Univoribs, F.M.B. 2002, Ago Iwoye, Nigeria.
}

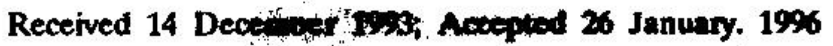

\section{ABSTRACT}

A total of 252 fresh table eges sorted into standard, large and extra-large sizes were either refrigerated or held at room temperature and used to study their weekly weight losses (WL), specific gravity (SG), egg index (EI), yolk index (YI) and albumen height (AH) over a six week period. The results showed that among room-stored eggs there were declines $(\mathrm{P}<0.01)$ in $\mathrm{AH}, \mathrm{YI}, \mathrm{SG}$ and EI but an increase in WL with increased egg size. Similar trends in response to long storage were observed except that EI was not affected $(P>0.05)$. The depressive jutences of long storage and larger sizes on egg quality observed in room stored eggs diminished with refrigeration. The general patterns of quality deterioration show that, irrespective of egg size, six-week refrigerated eggs had better quality indices than one-week old room-stored eggs. There was no significant $(P>0.05)^{\prime}$ influence of egg size on quality changes during storage. Based on the results, it was concluded that in the absence of refrigeration and when eggs are sold in assorted sizes, table eggs should be consumed within 2 weeks of lay and larger eggs should be used first. Key words: Egg size, Storage method, Egg quality.

\section{INTRODUCTION}

It is necessary to deliver eggs to the consumers while fresh because it is a delicate food product subject to rapid deterioration. In addition, the shell egg does not lend itself to accurate determination of the internal quality. Many years ago, consumers judged egg freshness by submerging the egg in brine. Fresh eggs normally sank while the stale ones floated. Although freshness does not affect the nutrient quality, it does influence the cooking and functional qualities of the eggs (American
Eggi Board, 1981; Ikeme, 1987).

Several methods of preserving freshness of table eggs have been employed (Olomu, 1975; Ikeme, 1987 and Coleman, 1988) but. cold storage at below $13^{\circ} \mathrm{C}$ has been found most ideal (American Egg Board, 1981). The evolution of efficient evacuation and transportation systems in some parts of the world has made it possible for eggs to reach the consumers within hours of being laid. However, the absence of these facilities and services in Nigeria, apart from causing delays in delivery to consumers, cannot guarantee the quality of such eggs. Invariably, egs of various hidden stages of deterioration flood the market. In addition, eggs hitherto offered for sale in various separate sizes are now sold in mixed sizes thereby depriving consumers of choice of egg sizes. Separate influences of egg size or storage temperatures on egg quality variations during storage or periodic egg quality surveys have been reported by some workers (Fry and Newell, 1957; Korslund et al, 1957; Kraft et al, 1958; Card and Nesheim, 1975; Davies et at, 1986 and Ikeme, 1987). However, there is paucity of infogmation as to the effects of the interdependence of these factors on quality variations during storage. This becomes very relevant iven the prevailing egg marketing situation in this country. This study evaluates the interactive influences of egg size and storage methods on changes in internal quality and some external physical characteristics of table eggs at varying periods of storage after lay.

\section{MATEAJALS AND METHODS}

\section{Egg Serinuson and Stonge:}

A total of $25<$ brown presorted table egs were obtained from 39-week old Brown Olympia birds in the Poultry Unit of the College of Agricultural Sciences, Ogun State 
University, Nigeria. The birds were fed on normal commercial layers mash containing 15.8\% Protein and 3.02 Mcal/kg-ME. All eggs were sorted and necessary sampling and measurements carried out within eighteen hours of lay. Eggs were classified into weight categories as described by David et al, (1986) and shown in Table 1. Sampling was not possible for the small size eggs apparently due to the flocks advanced age in lay. Eggs were weighed on the first day of collection and the weights inscribed on their shells. Each egg size was divided into two lots and each further divided into seven weight equalised groups of six eggs. One lot was stored in the refrigerator at an average temperature of $8.25^{\circ} \mathrm{C}$ while the other lot was stored at an average room temperature of $28.08^{\circ} \mathrm{C}$ and a relative humidity of $81 \%$.

\section{Egg Measurements:}

The initial values of egg index (EI) weight

$$
\text { TABLE ?: CLASSES OF TABLE EGGS }
$$

AND THE MEAN WEIGHTS OF FAESORTED EGGS

\begin{tabular}{llc}
\hline Egg Size & $\begin{array}{c}\text { Minimum* } \\
\text { Weight }(\mathbf{g})\end{array}$ & $\begin{array}{c}\text { Mean Weights } \\
\text { (g士s.e.) of sorted } \\
\text { eggs }(\mathbf{n}=\mathbf{8 4})\end{array}$ \\
\hline Small & 45 & \\
Standard & 50 & $52.30 \pm 0.17$ \\
Large & 55 & $56.93 \pm 0.15$ \\
Extra-Large & 60 & $64.58 \pm 0.51$ \\
\hline
\end{tabular}

"Weight Classification described by Davis $e t$ al (1986)

loss (WL) and specific gravity (SG) of the intact egg and albumen height ( $\mathrm{AH}$ ) and yolk index (YI) of the same egg when opened were determined with one group of six eggs from each of the six size by storage method treatment combinations. All measurements were repeated at weekly intervals for a total of six weeks using the same number of eggs for each treatment combination. All refrigerated eggs were brought to room temperature before evaluation. Egg index was measured as the ratio of the distance along the widest width to that of the longest length and expressed as a percentage. The linear measurements were taken with vernier calipers. Weight losses were measured by the difference in weights between the initial weight and weights after 1,2,3,4,5 and 6 weeks. The weight difference was expressed as a percentage of the fresh egg weight. Specific gravity was estimated as a ratio of egg weight to its volume and expressed as $\mathrm{g} / \mathrm{ml}$. The egg volume was estimated by water displacement method as described by Carter (1968). Yolk index was estimated as the ratio of yolk height to the mean of its width from two different expanses. The height was measured using a tripod micrometer and the width was measured using the vernier calipers. Albumen height measured with the tripod micrometer, was taken on the thick albumen midway between its outer and yolk edges but away from the chalazae.

\section{Statistical Analyses:}

All data were analysed using the factorial analyses of variance with egg size, storage method, storage period and their various interactions as sources of variations. Means were separated using the Duncan's New Multiple Range Test as described by Steel and Torrie (1980).

\section{RESULTS}

The analysis of variance (Table 2) shows that storage method and period as well as thuir interactions influenced $(P<0.001)$ all measurements except the egg index with storage method having the most overiding effect in all cases. The egg size influenced YI $(P<0.01)$, WL and EI $(P<0.001)$ and $A H$ $(P<0.05)$ but had no significant influence $(P>0.05)$ on SG. Significant influence of size-by-storage method interactions were also observed on AH $(\mathbf{P}<0.01)$ and WL $(\mathbf{P}<0.001)$. Table 3 shows the interactive effects of size and storage method on various quality and physical characteristics of table eggs. Generally with room-stored eggs, while WL was on the rise, declines in AH, YI, SG and EI were observed as the-egg size increased. However, refrigerated eggs, apart from being better in quality than their respective room stored eggs, were not different across sizes. Table 4 shows the changes in quality characteristics of refrigerated and room- stored eggs during the six-week storage period. Generally as storagc 
QUALITY CHANGES IN STORED TABLE EGGS

TABLE 2: MEAN SQUARES OF ANALYSES OF VARIANCE FOR SOME EGG

OUAUT AND PHYSICAL CHARACTEPISTICS

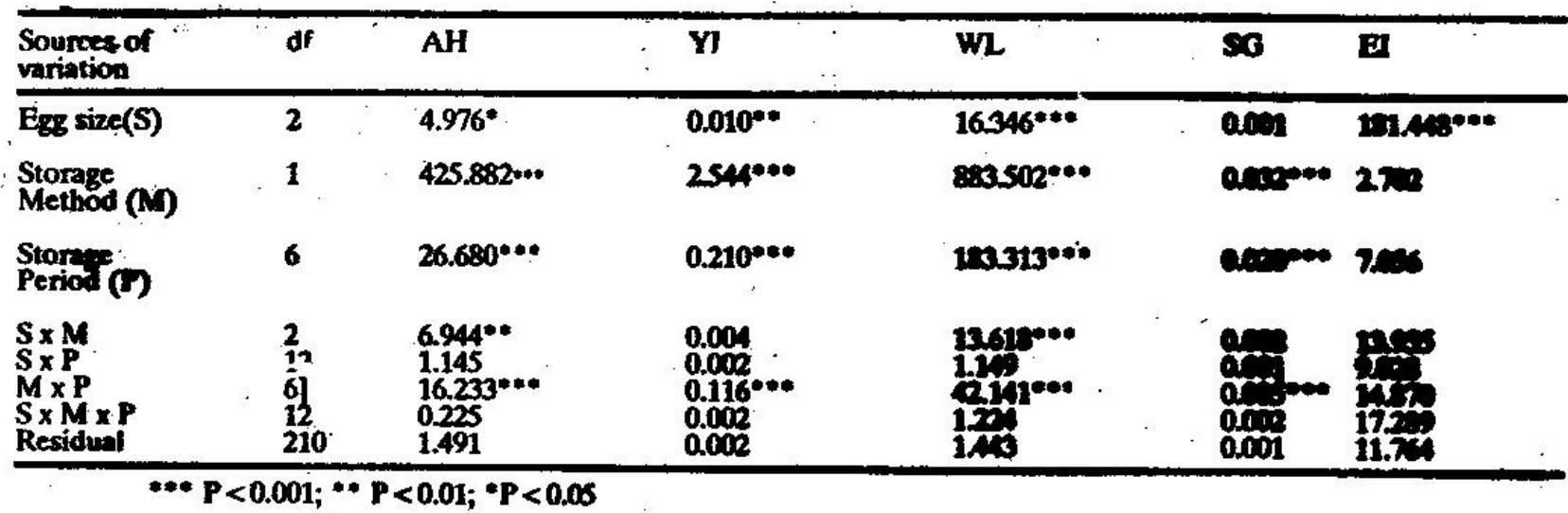

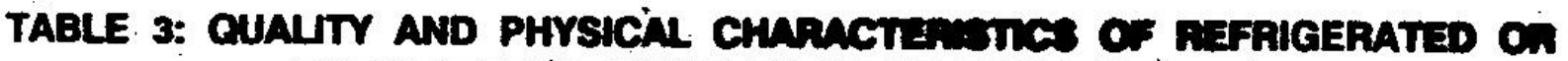

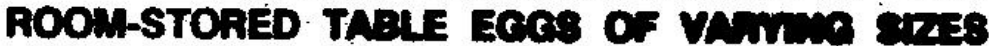

\begin{tabular}{|c|c|c|c|c|c|c|}
\hline Egs Sine & $\begin{array}{l}\text { Storase } \\
\text { Methos }\end{array}$ & AH & $\mathbf{n}$ & (4) & ) & $\mathbf{B}$ \\
\hline $\begin{array}{l}\text { Standand } \\
\text { Larze } \\
\text { Extri Lante }\end{array}$ & 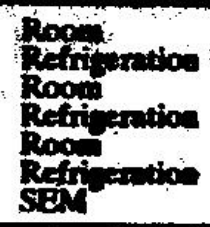 & $\begin{array}{l}3.90 \\
5.75 \\
3.25 \\
5.60 \\
2.6 \\
6.15 \\
0.16\end{array}$ & $\begin{array}{l}0.26 \\
0.43 \\
0.23 \\
0.40 \\
0.20 \\
0.42 \\
0.007\end{array}$ & $\begin{array}{l}4.75 \\
1.75 \\
5.216 \\
1.75 \\
6.44 \\
1.756 \\
0.185\end{array}$ & $\begin{array}{l}10 \\
10 \\
100 \\
10 \\
100 \\
100 \\
000\end{array}$ & 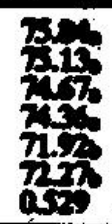 \\
\hline
\end{tabular}

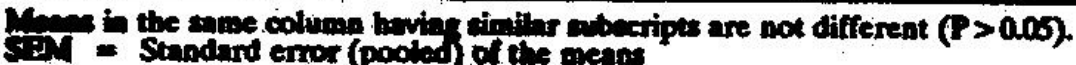

lengthened, there were continuosly increasing gaps in quality characteristics between refrigerated and room-stored eggs with the former being better in all cases. For the entire storage period, refrigerated egos had $\mathrm{YI}$ decline from 0.45 to 0.38 or $16 \%$ decline. The YI of refrigerated egs after six weeks was higher than the $\mathrm{Y}$ value of 0,31 recorded for room-stored egse after the first week of storage. At the end of six weeks, room-stored eggs had YI declines of about $77 \%$ from its initial value of 0.47 to 0.11 . The trend in WL indicated that unrefrigerated eggs recorded WL value about seven times that for refrigerated eggs after one week of storage. This indicated that refrigerated eggs lost in one week a weight equivalent lost by room-stored eggs in one day during the first week of storage. Subsequent comparative losses were not as high. A total of $3.37 \%$ WL observed for refrigerated eggs after six weeks storage was similar to $3.55 \%$ recorded for room-stored eges just after the first week of storage. The maximmum mean WL value of $10.03 \%$ observed for unrefrigerated eggs at the end of the storage period was about three times the value recorded for refrigerated eggs.

Table 4 also shows a rapid initial decline in AH from a value of $6.32 \mathrm{~mm}$ to $4.02 \mathrm{~mm}$ or $36 \%$ decline for room-stored egess. Subsequent decline in $\mathrm{AH}$ for the eggs was gradual and appeared to level off after 2 weeks of storage. For refrigerated eggs the decline in AH was minimal with an initial value of $6.26 \mathrm{~mm}$ decreasing to $5.46 \mathrm{~mm}$ after the sirth week. Refrigerated eggs showed no significant $(P>0.05)$ change in SG throughout the storage period. However, room-stored eggs declined significantly $(P<0.01)$ after two weeks of storage. The rate of decline in SG slowed down afterwards and levelled off after 4 weeks of storage. The lowest SG value of $1.07 \mathrm{glml}$ recorded after 6 weeks for refrizerated eggs did not differ significantly $(P>0.05)$ from $1.06 \mathrm{~g} / \mathrm{ml}$ recorded for room stored eggs after 3 weeks storage. The observed decrease in SG after 6 weeks of storage for refrigerated and room-stored eggs constituted 3.13 and $7.82 \%$ respectively. 
TABLE 4: CUAUTY AND THIIPN CHRACTEMSTCS OF REFRIGERATED AND

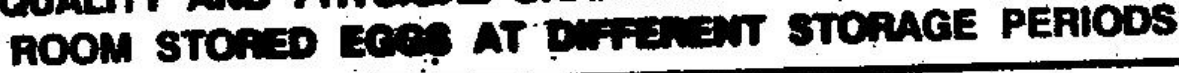

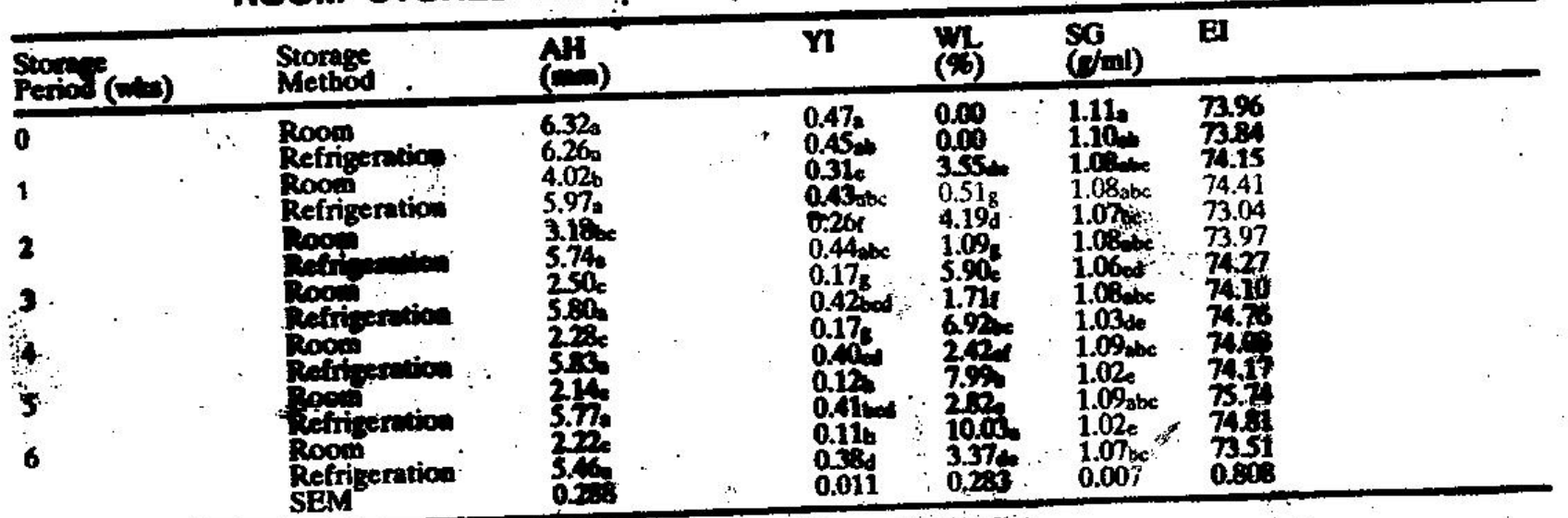

Means in the same column having similer subscripts are not different $(P>0.06)$

$\mathrm{SEM}=$ Standard error (pooled) of the means

\section{Ethousson}

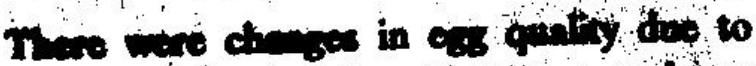

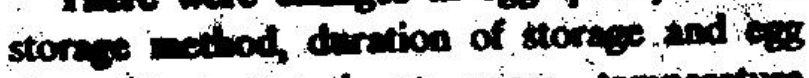
sive tored at room temperature deteriorated more in quality particularly in the first week of storage than those refrigerated. This is in expenent with the reports of Fry et al (1965) ad Beme (1987), who reported that quality decline of unrefrigerated eggs in the first seven duy was greater than that over a period of 7 to 14 days or 14 to 21 days. On the average, the rates of decline in $\mathrm{AH}, \mathrm{YI}$ and WL of room-stored eggs were respectively 6.3 , 5.3 and 2.6 times the yalues for refrigerated eggs. Abumen quality was measured in terms of its height and not converted to Haugh Unit (HU). This was done to avoid the bias inherent in the measurement of $\mathrm{HU}$ as reported by Eisen et al (1962). The authors revealed that $H U$ overestimates the albumen quality of eggs smaller than $56.5 \mathrm{~g}$ and underestimates the albumen quality of those greater than $56.5 \mathrm{~g}$. From the third week, the AH of room-stored eggs had declined below $3.0 \mathrm{~mm}$. In addition, the thick and thin albumen had become miscible and inseparable. It had also detached from the yolk and become watery. Refrigerated eggs showed none of these sigm even at the end of six weeks of storage. The albumen was still firm and attached to the yolt and the thick and thin albumen were still discernible.

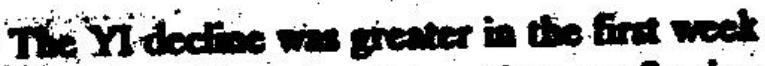

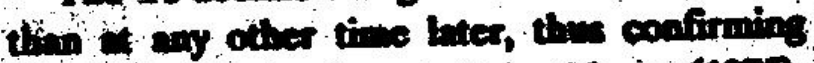

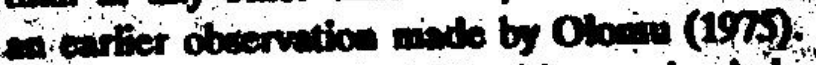

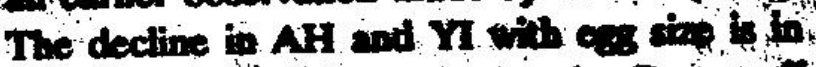
agrecement with earier repoits bs Ro woof and Rombroff (1949) and David a-d (1909), The trends in the decline of AIS an is

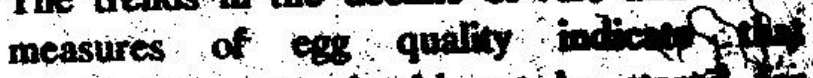
consumable eqos should not be tout fo more than two weeks under root temperature. In fact Olomu (1975) and testo (1990) had suggested the disposal of thite exs within one week of lay in abuence of cold storage. The significant, influeinge of $\mathrm{cgs}$ size-by-storage period interaction onality and physical characteristics of tablo ent in indication that the two foctenthed independent influences on testots measurements. It is expected therefort tho the variations observed in respones to profod of storage would bold for the rango of $\mathrm{co}$ sizes tested in this study. If increased weigh losses with size observed it roapstored egre could be due to larger surfice area How and positive correlation have been shown to erity between egg weight and sinface men (Orte), 1975). Losses in egs woight are due to gitwhy diffusion of moisture and gases (liemes 108 ) The rate of diffusion is increased $4 \mathrm{fol}$ temperature. Egos unde refiperation ure

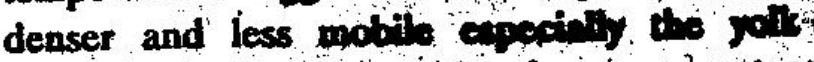
(Baker, 1953) preaumbly to to tors proportion of fat content (Marion a of 1960). Heath of al (1976) have showe that ace after, 
lay ard temperature have very strong intluence on egg qualiky. However, influence of age on egg quality is greatly reduced in refrigeration. It is apparent from the resulks of-the current study that refrigeration suppressed not only the effects of sturage perind but also effectively the infucince of ezse (Table 3).

The width and length of the eggs as components of egg indices or shape did not change throughout the six week period. The indices of the Standard and Large eggs were, however, higher than for Exara-large eggs. It is not known if variations in EI could be directly linked to changes in egg quality. It is, however, known that increase in egg length and breadth initeise surface area of shell eggs (Carter, 1975; Olori and Sonaiya, 1992). Larger surface area, in turn, enhances outward diffusion of volatile materials, hence increased $W L$ as observed in Extra-large eggs. Losses in egg weight while the egg volume remains unchanged will undobtedly restas is decline in

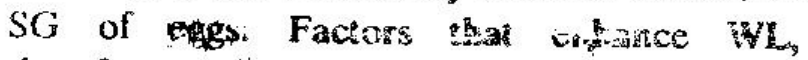
therefore, wit result in SC: decline. AS revealed in this study, storage preriod and nethod, more than size, have greai inituence in this regard.

The pattern of es purchase in this country is such that majority of consumers purchase eggs in small quantities more from retailers than wbolesalers or at farm points. In fact for most consumers, especially those without cold storage facilities, eggs are purchased only if and when the need arises. The eggs are maintained at ambient temperature by most if not all the dealers and are usually offered for sale in assorted sizes. The volume of sales obviously determines how long an egg stays with the retailes ond invariably its internal quality status at the time of sale. Since it is difficult for consumers to determine the age of an egg, it is advisable that his choice be made among the smaller eggs. The alternative is to purchase, at farm locations, eggs that can be consumed within two weeks. Even in such a situation larger eggs are better consumed first. It should however be born in mind that the quality of an egg normally at its best when freshlv laid strongly influences its quality at any particular time (Card and Nasheim, 1975; Davis et al, 1986). The initial quality itself is also influenced by many factors including flock breed and strain, age in lay and diet (R-th al, 1960; Noles and Tindell, 1966; Davis a al 1986).

\section{REFERENCES}

AMERICAN EGG BOARD. (1981). Eggcyclopedia course of egg education. American egg board publication 1460. Renaissance Drive, Park Ridge. Illinois.

BAKER, R.L. (1953). The effect of Large versus small-end up on assigned egg drainage. Poultry Sci. 32: 1090-1093.

CARD, E.L. and NESHEIM, M. C. (1975). Poultry production. Published by Lea and Febiger. 11th edition.

CATER, T.C. (1058). The hen's egg: A mathematical model with three parameters. 8. Portlry Sci. 9: 165-171.

C. ETER, r.C.1975 The her's egg. Estimation of ans cuperficial area and egg volume using Eneasuremeats from fresh eyg weights, shell iength and breadth alone or in combination. Br. Poultry Sci. 16:541-543.

CuLEMAN, A.M. (1988). The impact of temperature on quality control (1). Poultry .4(3); 15. Published by Misset International. The Netherlands.

DAVIS, B.M., O'ROUK P.K and STEPHENSON, H. (1986). The quality of eggs on farms and at retail outlet in North Queensland during summer and winter. Queenstand J. Agric. Animal Science. 43(2): 159-168.

EISEN, EJ., BOHREN, B.B and McKEAN, E.H. (1962). The Haugh unit as a measure of egg albumen quality. Poultry Sci. 41: 1461-1468.

ESSIEN, A.I. (1990). Egg quality trats and their interrelationships as affected by storage method and duration of storage in a humid wet climate. Beitr. trop. Landwirtsch. Vet. Med. 28H. 3, 345-353. 
FRY, J.L. and NEWELL, G.W. (1957): Management and holding conditions as they affect the interior quality of eggs. Poultry Sci. 36: 240-246.

FRY,J.L., MOORE, J.S. and O'STEEN, A.W. (1963). Strain differences and initial quality relationships to rate of interior egg quality decline. Poultry Sci. 32:902.

HEATH, J.L., DUNN, N.A. and LANA, D.P. (1976). Factors affecting adhering albumer that can be controlled by consumers. Poultry Sci. 55(5): 1999-2000.

IKEME, A.I. (1987). Effect of oil treatment and storage temperature on some selected physical and functional Properties of shell Eggs. J. Food Agric. 1: 17-21.

KORSLUND, H.J., MARISON, W.W. and STADELMAN, W.J. (1957). Some factors affecting quality loss in shell eggs. Poultry Sci. 36:338-341.

KRAFT, A.A., McNALLY, E.H. and BRANT, A.W. (1958) Shell quality and bacterial infection of shell eggs. Poultry Sci. 37: 638-644. MARION, J.E.; WOODROFF,J.G.; COOK, R.E. (1965). Some physical and chemical properties of eggs frrm hens of five different stocks. Poultry Sci. 44:529-534.
NOLES, R.K. and TINDELL, D. (1966): observations on interrelationships of egg quality traits and their associaton with seasons, age and strain of bird. Poultry Sci. 46: 943-953.

OLOMU, J.M. (1975). Effect of traditional methods of storage on egg quality. Nig. $J$. Anim. Prod. 2: 182-187.

OLORI, V.E. and SONAIYA, E.B. (1992). Effect of length of lay of Nigerian indigenous chickens on their egg composition and shell quality. Nig. J. Anim.Prod. 19:95-100.

ROMANOFF, A.L. and ROMANOFF, A.J. (1949). The Avian Egg. John Wiley and Sons Inc. New York.

RUTH, J., GLADYS, E.V., ROGLER,J.C. and STADELMAN, W.J. (1960). Functional properties and flavour of eggs laid by hens on diets containing different fats. Food Tech. 14: 418-422.

STEEL, R.G.D. and TORRIE, J.H. (1980). Principles and Procedures of statistics. 2nd ed. McGraw Hill Books Company Inc., New York 